\title{
EXOGENOUS CONTROL OF CARDIAC GENE THERAPY: EVIDENCE OF REGULATED MYOCARDIAL TRANSGENE EXPRESSION AFTER ADENOVIRUS AND ADENO-ASSOCIATED VIRUS TRANSFER OF EXPRESSION CASSETTES CONTAINING CORTICOSTEROID RESPONSE ELEMENT PROMOTERS
}

Leonard Y. Lee, MD ${ }^{\mathrm{a}, \mathrm{b}}$

Xiaohuai Zhou, $\mathrm{PhD}^{\mathrm{a}, \mathrm{b}}$

Dean R. Polce, BS ${ }^{a, b}$

Tarek El-Sawy, BS ${ }^{\mathrm{a}, \mathrm{b}}$

Shailen R. Patel, MD a,b

Geeta D. Thakker, $\mathrm{PhD}^{\mathrm{b}}$

Ko Narumi, MD, $\mathrm{PhD}^{\mathrm{a}}$

Ronald G. Crystal, MD

Todd K. Rosengart, $\mathrm{MD}^{\mathrm{b}}$
Objective: Because of the relative inaccessibility of the heart for repeated gene therapy, it would be useful to regulate the expression of transgenes delivered in a single dose of a gene therapy vector. Incorporation into the vector of a regulatable promoter that is responsive to pharmacologic agents that are widely used and well tolerated in clinical practice represents such a control strategy. Methods: A replication-deficient adenovirus or an adeno-associated virus containing a chimeric promoter composed of 5 glucocorticoid response elements and the murine thrombopoietin complementary DNA (AdGRE.mTPO or AAVGRE.mTPO) was administered to the hearts of Sprague-Dawley rats. Platelet levels were evaluated as a reporter of transgene activity with or without dexamethasone. For comparison, rats received a control adenovirus vector, AdCMV.mTPO or AdCMV.Null, and the control adeno-associated virus vector AAVCMV.luc, which encodes for the firefly luciferase (luc) gene. Results: Platelet elevation in the AdGRE.mTPO group peaked 4 days after dexamethasone administration, with a return to baseline 1 week after the initial corticosteroid dose. Subsequent dexamethasone administration at 2 and 4 weeks resulted in similar but progressively decreased responses. The AAVGRE.mTPO group had 5 peak platelet levels to a minimum of 2.2-fold with respect to baseline without diminution with subsequent dexamethasone administrations out to 169 days. In contrast, the AdCMV.Null and AAVCMV.luc groups demonstrated no increase in platelet counts and the AdCMV.mTPO group demonstrated a slow rise to a single peak platelet count independent of dexamethasone administration. Conclusion: It may be possible to control on demand the expression of a gene transferred to the heart. This strategy should be useful in cardiac gene therapy. (J Thorac Cardiovasc Surg 1999;118:26-35)
G ene transfer vectors, together with their promotertransgene expression cassettes, can be considered as drug delivery systems in which the protein product of the transgene evokes the desired therapy. Like other drug delivery systems, gene transfer vectors provide

From the Division of Pulmonary and Critical Care Medicine a and Department of Cardiothoracic Surgery, ${ }^{\mathrm{b}}$ The New York Presbyterian Hospital-Weill Medical College of Cornell University, New York, NY.

Supported in part by the National Institutes of Health, National Heart, Lung and Blood Institute grants R01 HL 57318, P01 HL59312; the Jeffry M. and Barbara Picower Foundation, Palm Beach, Fla; Will Rogers Memorial Fund, Los Angeles; GenVec, Inc, Rockville, Md; and the Thoracic Surgery Research Foundation, Chicago, Ill.

L.Y.L. and X.Z. contributed equally as principal investigators in this study. R.G.C. and T.K.R. contributed equally as senior investigators in this study. different pharmacokinetics of the protein product depending on a variety of factors, including the vector, the dose, the route of administration, the target organ, the promoter, the transgene, and any antivector host defenses. ${ }^{1,2}$ The concept of pharmacokinetics of the protein

Received for publication Oct 12, 1998; revisions requested Nov 30, 1998; revisions received Jan 25, 1999; accepted for publication Feb 26, 1999.

Address for reprints: The New York Presbyterian Hospital-Weill Medical College of Cornell University, 525 East 68th St, Suite F2103, New York, NY 10021.

Copyright (C) 1999 by Mosby, Inc.

$0022-5223 / 99 \$ 8.00+0 \quad \mathbf{1 2 / 1 / 9 8 4 3 8}$ 


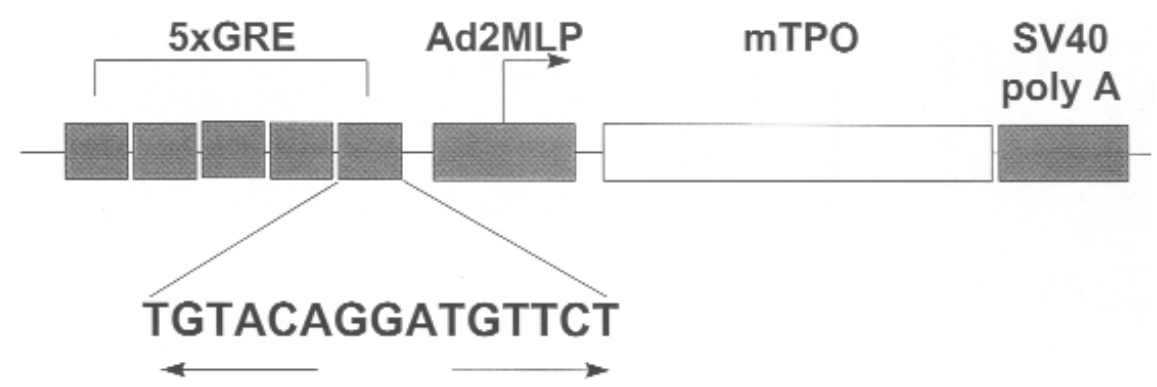

Fig 1. Expression cassette with chimeric GRE promoter $(5 x G R E)$ including 5 GREs from the rat tyrosine aminotransferase gene inserted upstream of Ad-2 major late promoter $(A d 2 M L P)^{8}$ with mTPO complementary DNA as reporter gene and simian virus 40 (SV40) polyadenylic acid (poly A) stop signal. ${ }^{9}$

product is particularly critical in organs for which administration of the gene transfer vector is cumbersome or carries a risk to the recipient. The heart is one such organ.

Although the heart is accessible for gene transfer by direct intramyocardial injection from the epicardial or endocardial surfaces and through the coronary arteries, ${ }^{3-6}$ such transfers are invasive procedures that are usually not performed repetitively in a given patient. In the context of these considerations and the increasing interest in cardiac gene transfer for the treatment of coronary vascular insufficiency and the treatment of heart failure, it is desirable to have a repertoire of cardiac gene transfer strategies that exhibit different pharmacokinetics of the protein product coded by the transgene in the vector expression cassette.

One strategy to achieve different pharmacokinetics of the transgene product is through controlling expression of the transgene with different promoters. In this context, the purpose of this study was to compare gene expression patterns after intramyocardial gene transfer of an expression cassette with an active constitutive promoter to a cassette with a promoter that is regulated by administration of an exogenous drug. To accomplish this, we used adenovirus (Ad) and adeno-associated virus (AAV) vectors to transfer the expression cassettes, because Ad and AAV vectors efficiently transfer expression cassettes to cardiac myocytes after direct intramyocardial administration of the vector. ${ }^{5,6}$ For the constitutive promoter we used the cytomegalovirus (CMV) early-intermediate promoter-enhancer ${ }^{7}$ and for the regulatable promoter we used a chimeric promoter containing multiple tandem glucocorticoid response elements (GREs), a promoter responsive to systemically administered glucocorticoids. ${ }^{8,9}$ For the transgene we used the murine thrombopoietin (mTPO) complementary DNA because of the ability of the secreted thrombopoietin to induce a rise in blood platelet levels, a reporter system that permits repetitive measurement in the same experimental animal with a minimal amount of blood sampled and minimizes interanimal variability in response to expression of the transgene. ${ }^{9}$ The data demonstrate very different transgene product pharmacokinetics after in vivo intramyocardial expression cassette transfer with a constitutive promoter and a regulatable promoter, differences that may be exploited for different cardiac gene transfer applications.

\section{Methods}

Gene-transfer vectors. Three Ad vectors were used for the study; all were based on the Ad5 backbone with deletions of $\mathrm{E} 1$ and $\mathrm{E} 3$ and the expression cassette in the E1 region. Both the CMV.mTPO and GRE.mTPO expression cassettes in Ad vectors have been characterized in other organ systems. The AdCMV.mTPO vector expresses the murine thrombopoietin complementary DNA under control of the constitutive cytomegalovirus early-intermediate promoter-enhancer. ${ }^{7}$ The AdGRE. $m T P O$ vector is identical to the AdCMV.mTPO vector except that the $m T P O$ complementary DNA is under control of the chimeric GRE promoter that uses 5 GREs from the rat tyrosine aminotransferase gene in tandem with the insertion of Ad2 major late promoter TATA box-initiation site ${ }^{8,9}$ (Fig 1). The AdCMV.Null vector, which served as a negative control, is identical to the AdCMV.mTPO vector but contains no transgene in the expression cassette. ${ }^{10}$ All the Ad vectors were purified by cesium chloride density gradient ultracentrifugation, titered by plaque-forming assay on 293 cells, and demonstrated to be free of replication competent Ad. ${ }^{11,12}$

The AAV vector AAVCMV.luc included the AAV terminal repeats and an expression cassette of the cytomegalovirus early/intermediate promoter-enhancer and the luciferase (luc) reporter gene. The proviral plasmid pAAVCMV.luc was constructed by ligating the XhoI-SalI fragment of pTRUF2 containing the AAV terminal repeats and the CMV promoter with the XhoI-SalI fragment of pGL2-Basic containing the luciferase complementary DNA and the simian virus 40 polyadenylic acid stop signal (Promega Corporation, Madison, Wis). The pAAVGRE.mTPO was constructed by inserting into the AAV backbone, the BglII-digested pTRUF2 

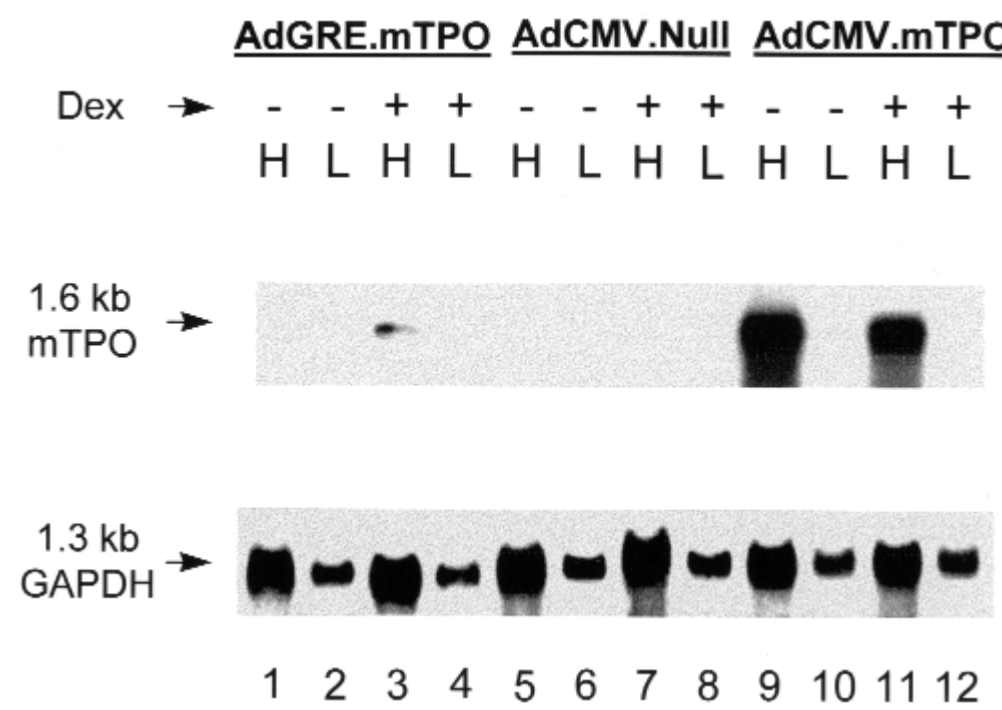

Fig 2. Thrombopoietin messenger RNA levels assessed in heart $(H)$ and liver $(L)$ of animals 48 hours after intramyocardial administration of AdCMV.mTPO, AdGRE.mTPO, or AdCMV.Null (each $10^{9} \mathrm{pfu}$ ) with $(+$ ) and without (-) concomitant systemic dexamethasone (Dex) therapy. Animals were sacrificed 48 hours after vector administration and hearts and livers were excised and assessed for messenger RNA levels by Northern analysis. GAPDH served as internal control for all lanes. Sizes of $m T P O$ and GAPDH transcripts are indicated.

fragment, with the $\mathrm{Xba \textrm {I }}$ fragment from the pGRE.mTPO ${ }^{9}$ containing the mouse thrombopoietin complementary DNA driven by the dexamethasone-inducible GRE5 promoter (Fig 1). AAV vectors were produced by transfecting 293 human embryonic kidney cells (American Type Culture Collection, Manassas, Va) with a mixture of 3 plasmids: an AAV proviral plasmid, pACG2 (containing the AAV rep and cap genes), and pXX6 (containing the Ad E2A, E4, and VA genes). The resulting virions were purified with a cesium chloride gradient followed by dialysis in phosphate-buffered saline solution, $\mathrm{pH}$ 7.4. ${ }^{13}$ The activities of the AAV vectors in infectious units (iu) were determined by a replication center assay. ${ }^{14}$

Experimental design. Male Sprague-Dawley rats (250$350 \mathrm{~g}$ ) were from Charles River (Charles River Laboratories, Inc, Wilmington, Mass) or Taconic (Germantown, NY). The body weights of rats were matched for each experiment. Each experiment included 3 animals for each data point represented. A total of 36 animals were used for this study (30 for repetitive platelet evaluations and 6 for Northern analysis).

Evaluation of the in vivo responses to dexamethasone of the constitutive CMV promoter and the inducible GRE promoter was performed by administering the Ad vector (AdCMV.mTPO, AdGRE.mTPO, AdCMV.Null all $10^{9}$ plaqueforming units [pfu]) and AAV vectors (AAVGRE.mTPO or AAVCMV.luc, $10^{9} \mathrm{iu}$ ) in a single apical myocardial injection in the rats after a sternotomy under anesthesia. ${ }^{15}$ Animals were sedated with an intraperitoneal injection of $80 \mathrm{mg} / \mathrm{kg}$ ketamine and $5 \mathrm{mg} / \mathrm{kg}$ xylazine. Once an adequate plane of anesthesia was accomplished the rats were intubated with a 20-gauge angiocatheter. A left parasternotomy was performed with the assistance of a rodent ventilator (Harvard
Apparatus, Inc, Holliston, Mass), gaining full exposure to the heart. An apical injection of vector was administered in a volume of $50 \mu \mathrm{L}$ (vector diluted with phosphate-buffered saline solution, pH 7.4; BioFluids, Rockville, Md). The chest was closed in layers. Any remaining air in the thoracic cavity was aspirated with an indwelling angiocatheter and $10-\mathrm{mL}$ syringe. Once the animals were spontaneously breathing, the endotracheal tube was removed and the animals were allowed to recover. No operative deaths were encountered in this study. The AdCMV.mTPO group received no therapy (no dexamethasone group) or $0.75 \mathrm{mg} / \mathrm{d}$ dexamethasone intraperitoneally on 3 consecutive days after vector administration. The AdGRE.mTPO and AdCMV.Null groups received no therapy or $0.75 \mathrm{mg} / \mathrm{d}$ dexamethasone on 3 consecutive days after vector administration and starting days 17 and 31. The AAVGRE.mTPO and AAVCMV.luc groups received no treatment or $0.75 \mathrm{mg} / \mathrm{d}$ dexamethasone on 3 consecutive days 7 days after vector administration and starting on days $27,34,97$, and 165 days. The animals were subsequently evaluated for expression of $m T P O$ messenger RNA levels and platelet levels as described here.

Northern analysis. The Ad vectors were used to evaluate upward regulation of the $m T P O$ complementary DNA in the GRE.mTPO cassette transferred to the hearts of SpragueDawley rats. The AdGRE.mTPO, AdCMV.mTPO, and AdCMV.Null vectors were administered to the hearts of the rats as described, with and without dexamethasone. Animals were sacrificed 48 hours after vector administration and the hearts were excised and homogenized. Total messenger RNA (total $10 \mu \mathrm{g}$ ) was isolated with guanidine isothiocyanate phenol-chloroform extraction, ${ }^{16}$ separated on a $1 \%$ agarose gel 


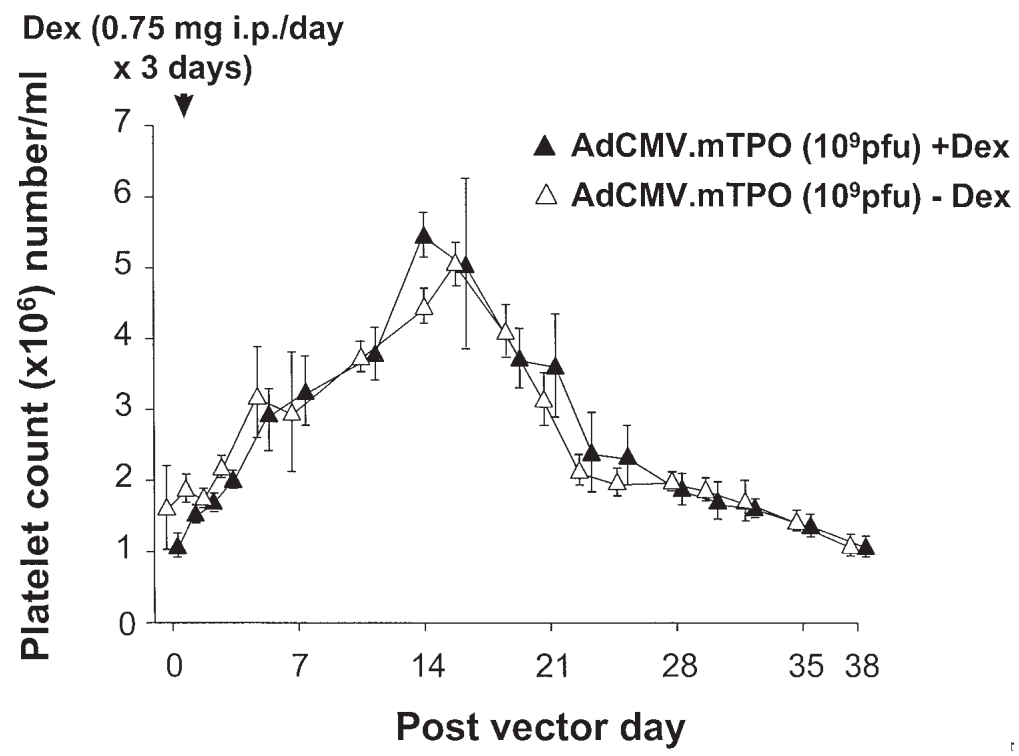

Fig 3. Blood platelet levels after intramyocardial administration of AdCMV.mTPO vector alone or with concomitant administration of dexamethasone (Dex). Ad vector containing complementary DNA for $m T P O$ driven by CMV early promoter-enhancer (AdCMV.mTPO, $10^{9} \mathrm{pfu}$ ) was injected into left ventricular walls of male Sprague-Dawley rats. Animals were either treated intraperitoneally (ip) with $0.75 \mathrm{mg} / \mathrm{d}$ dexamethasone (filled triangles) or received no treatment (open triangles) for 3 consecutive days beginning on day of vector administration $(\mathrm{n}=3$, each treatment group). Blood platelet levels were assessed at regular intervals from samples drawn from tail vein. Data points represent mean of platelet counts (in $10^{6}$ cells per microliter); error bars indicate SE.

containing $2.2 \mathrm{~mol} / \mathrm{L}$ formaldehyde, transferred to a nylon membrane (NYTRAN; Schleicher \& Schuell, Inc, Keene, $\mathrm{NH}$ ), and hybridized with a phosphorus 32-labeled mTPO complementary DNA probe and a control glyceraldehyde-3phosphate dehydrogenase (GAPDH) complementary DNA probe ${ }^{17}$ prepared by random priming and evaluated by autoradiography. ${ }^{18}$

Platelet levels. Platelet levels were determined in a blinded fashion with a Neubauer hemocytometer (Fisher Scientific Worldwide, Laboratory Projects Division, Springfield, NJ) from blood samples drawn from the tail vein with a $20-\mu \mathrm{L}$ capillary pipette (Unopette; Fisher Scientific) 1 to 38 days after Ad vector administration or 1 to 174 days after AAV vector administration.

Statistical analysis. The results are expressed as mean \pm SEM. Statistical comparisons were made with the unpaired 2tailed Student $t$ test.

\section{Results}

Northern analysis. In animals that received the AdCMV.Null control vector no $m T P O$ messenger RNA was detectable in the heart or liver, independent of dexamethasone administration (Fig 2, lanes 5-8). Rats that received the AdCMV.mTPO vector demonstrated 1.6kilobase (kb) $m T P O$ messenger RNA transcripts in the heart with or without dexamethasone (lanes 9 and 11).
No $m T P O$ messenger RNA was detected in the liver, independent of dexamethasone treatment (lanes 10 and 12). In contrast, in rats that received intramyocardial AdGRE.mTPO 1.6-kb messenger RNA transcripts were observed in the hearts of only dexamethasone-treated animals (lane 3); no $m$ TPO messenger RNA was detected in the hearts of rats that received AdGRE.mTPO without concomitant dexamethasone treatment (lane 1). No $m$ TPO messenger RNA was observed in the livers of animals that received the AdGRE.mTPO vector, independent of dexamethasone treatment (lanes 2 and 4). In all animals the control GAPDH messenger RNA was expressed in heart and liver (lanes 1-12).

Platelet levels as a marker for murine thrombopoietin expression. Intracardiac administration of the positive control vector AdCMV.mTPO evoked a slow rise to a single peak platelet level at days 14 (with dexamethasone) to 15 (no dexamethasone) after vector administration, 6-fold higher than baseline platelet levels $(P<.005$ for day 15 without dexamethasone compared with baseline, $P<.005$ for day 14 with dexamethasone; Fig 3). The same pattern of rise and fall of blood platelet levels after AdCMV.mTPO administration was observed without dexamethasone or with dexamethasone administration, with a decline to baseline 


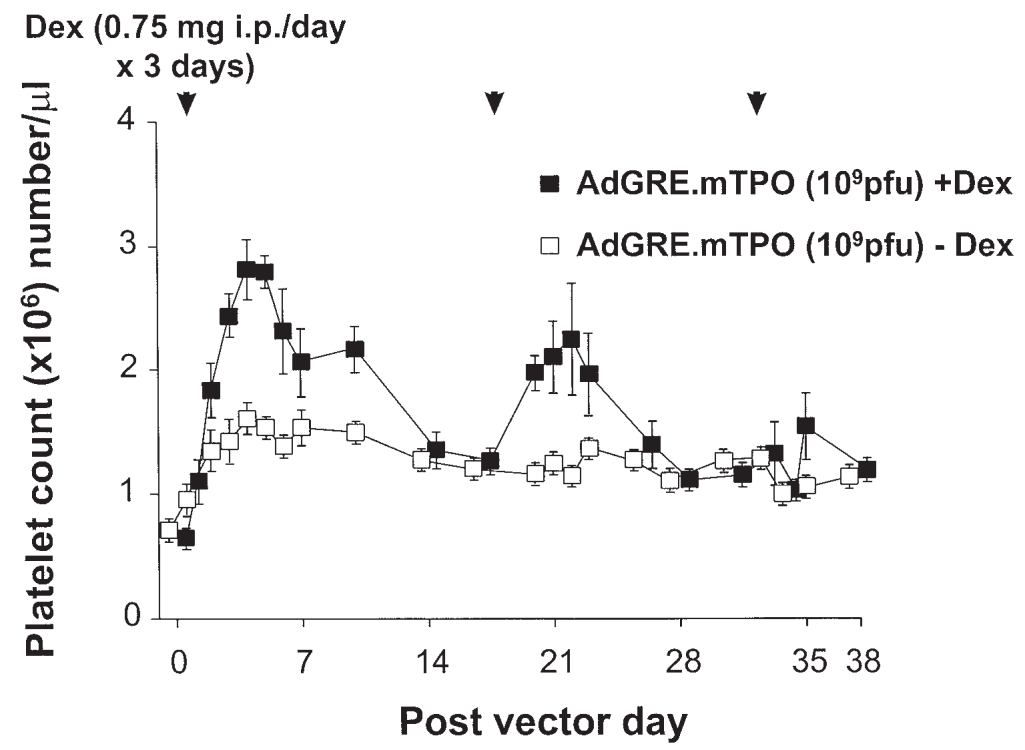

Fig 4. Blood platelet levels after intramyocardial administration of AdGRE. $m T P O$ vector alone or with intermittent administration of dexamethasone (Dex). Ad vector containing complementary DNA for $m T P O$ driven by GREs (AdGRE.mTPO, $10^{9} \mathrm{pfu}$ ) injected into left ventricular walls of male Sprague-Dawley rats. Animals were either treated intraperitoneally (ip) with $0.75 \mathrm{mg} / \mathrm{d}$ dexamethasone (filled squares) or received no treatment (open squares) for 3 consecutive days beginning on day of vector administration (day 0 ), day 17, and day 31 ( $\mathrm{n}=3$ for each treatment group). Blood platelet levels were assessed at regular intervals from samples drawn from tail vein. Data points represent mean of platelet counts (in $10^{6}$ cells per microliter); error bars indicate SE.

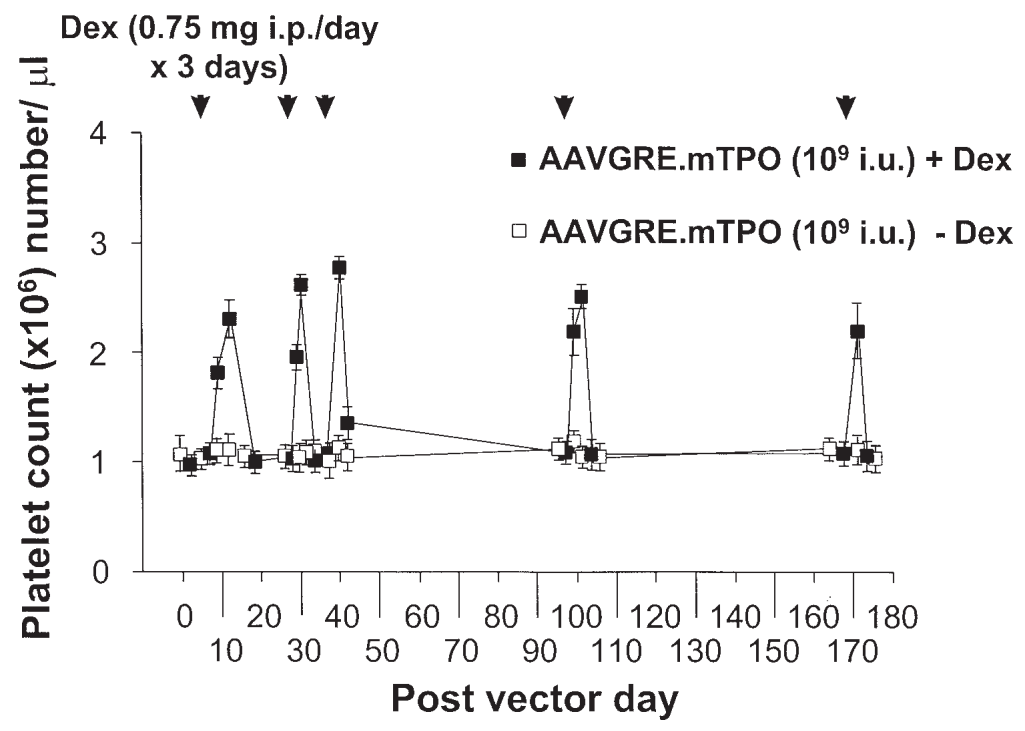

Fig 5. Blood platelet levels after intramyocardial administration of AAVGRE. $m T P O$ vector alone or with intermittent administration of dexamethasone (Dex). AAV vector containing complementary DNA for $m T P O$ driven by GREs (AAVGRE. $m T P O, 10^{9} \mathrm{iu}$ ) was injected into left ventricular walls of male Sprague-Dawley rats. Animals were either treated intraperitoneally (ip) with $0.75 \mathrm{mg} / \mathrm{d}$ dexamethasone (filled diamonds) or received no treatment (open open diamonds) for 3 consecutive days beginning 7 days after vector administration and on days 27 , 34, 97, and 165 ( $\mathrm{n}=3$ for each treatment group). Blood platelet levels were assessed at regular intervals from samples drawn from tail vein. Data points represent mean of platelet counts (in $10^{6}$ cells per microliter); error bars indicate SE. 


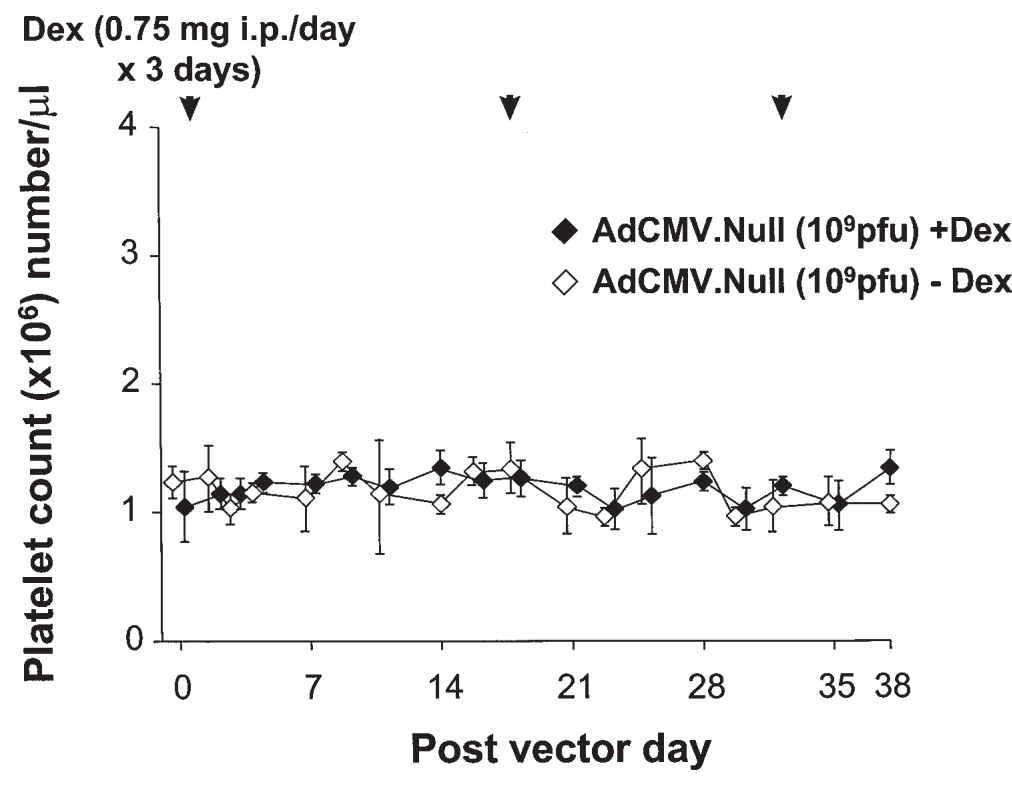

Fig 6. Blood platelet levels after intramyocardial administration of the AdCMV.Null vector alone or with intermittent administration of dexamethasone (Dex). A control Ad vector containing CMV early promoter-enhancer but no transgene (AdCMV.Null, $10^{9} \mathrm{pfu}$ ) was injected into left ventricular walls of male Sprague-Dawley rats. Animals were either treated intraperitoneally (ip) with $0.75 \mathrm{mg} / \mathrm{d}$ dexamethasone (filled diamonds) or received no treatment (open diamonds) for 3 consecutive days beginning on the day of vector administration (day 0), day 17, and day $31(\mathrm{n}=3$, each treatment group). Blood platelet levels were assessed at regular intervals from samples drawn from tail vein. Data points represent mean of platelet counts (in $10^{6}$ cells per microliter); error bars indicate SE.

levels by day $38(P>0.2$ for all comparisons at all time points of dexamethasone with no dexamethasone).

To evaluate the hypothesis that upward regulation of the GRE.mTPO expression cassette transferred to the heart by the AdGRE. $m$ TPO vector could be achieved by intermittent administration of dexamethasone, AdGRE. $m$ TPO was given as a single intramyocardial injection to male Sprague-Dawley rats with and without intermittent dexamethasone stimulation. Dexamethasone was given intraperitoneally at $0.75 \mathrm{mg} / \mathrm{d}$ on 3 consecutive days beginning on the day of vector administration (day 0) and on days 17 and 31. The platelet levels increased concomitantly with dexamethasone administration (Fig 4). Three peaks of blood platelet levels were observed, each occurring 4 to 6 days after the initiation of dexamethasone therapy: day 5 (3-fold above baseline levels, $P<.002$ compared with no dexamethasone), day 22 (2-fold above baseline levels, $P<.02$ compared with no dexamethasone), and day 35 (1.5-fold above baseline levels, $P<.04$ compared with no dexamethasone). All returned to baseline levels within 1 week of dexamethasone administration $(P>$ $.4, P>.2$, and $P>.4$, respectively, all cycles of dexamethasone administration compared with no dexametha- sone). Although there was an increase in platelet levels from baseline with each of the 3 cycles of dexamethasone administration in rats that received the AdGRE. $m T P O$ vector, the peak platelet levels gradually declined by the third cycle of dexamethasone administration (cycle 1 peak level on day 5 compared with cycle 2 peak level on day $22, P>.1$; cycle 2 peak level on day 22 compared with cycle 3 peak level on day 35 , $P>.08$; cycle 1 peak level on day 5 compared with cycle 3 peak level on day 35, $P<.004$ ).

To evaluate the hypothesis that long-term, repetitive upward regulation of the GRE.mTPO expression cassette transferred to the heart by the AAVGRE.mTPO vector could be achieved by intermittent administration of dexamethasone, AAVGRE. $m$ TPO was given as a single intramyocardial injection to male SpragueDawley rats with and without intermittent dexamethasone stimulation. Dexamethasone was given intraperitoneally on 3 consecutive days at $0.75 \mathrm{mg} / \mathrm{d}$ beginning 7 days after vector administration and then again on days $27,34,97$, and 165 . Five blood platelet level peaks were observed (minimum of 2.2-fold above baseline), each occurring 4 days after the initiation of dexamethasone therapy $(P<.0005$ for each peak com- 


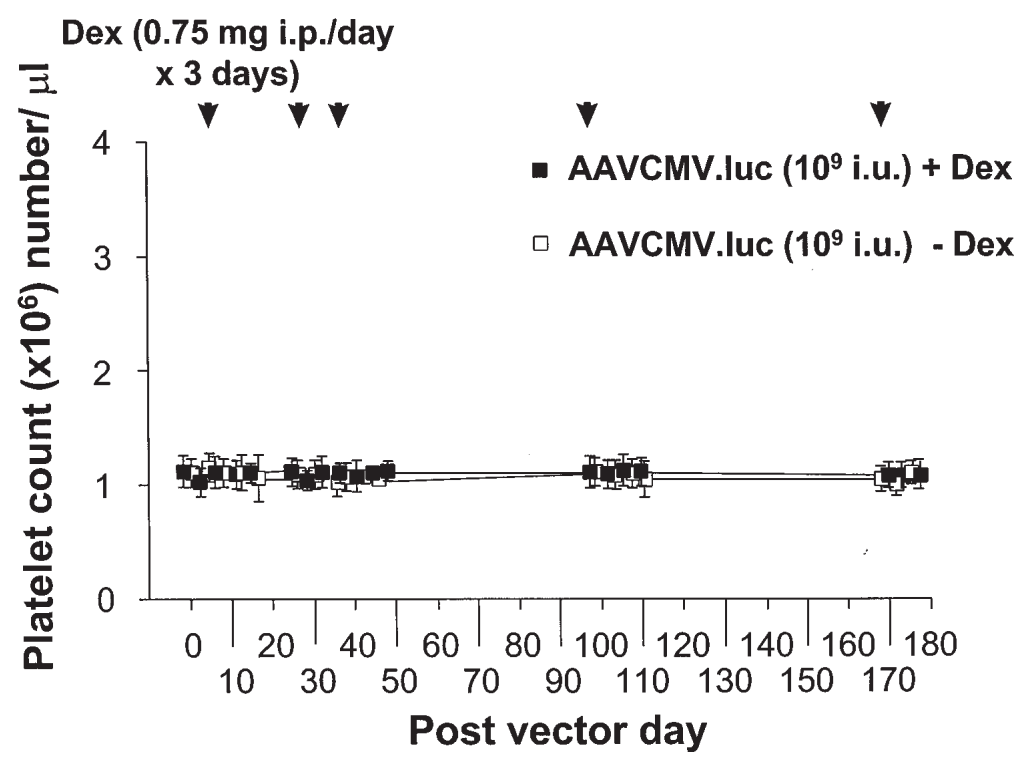

Fig 7. Blood platelet levels after intramyocardial administration of control AAVCMV.luc vector alone, or with intermittent administration of dexamethasone (Dex). An AAV vector containing the complementary DNA for the luciferase firefly gene containing the CMV early promoter/enhancer but no transgene (AAVCMV.luc, $10^{9} \mathrm{iu}$ ) was administered into the wall of the left ventricle of male Sprague-Dawley rats. Animals were either treated intraperitoneally (ip) with $0.75 \mathrm{mg} / \mathrm{d}$ dexamethasone (filled squares) or received no treatment (open squares) for 3 consecutive days beginning 7 days after vector administration, and on days $27,34,97$, and $165(\mathrm{n}=3$ for each treatment group). Blood platelet levels were assessed at regular intervals from samples drawn from tail vein. Data points represent mean of platelet counts (in $10^{6}$ cells per microliter); error bars indicate SE.

pared with no dexamethasone; Fig 5). In contrast to the AdGRE.mTPO vector, there was no attenuation of the platelet response to repetitive dexamethasone stimulation as late as 169 days after vector administration.

The increases in blood platelet levels associated with the administration of the AdGRE.mTPO or the AAVGRE.mTPO vector were not due to the dexamethasone per se because intermittent administration of dexamethasone after intramyocardial administration of the negative control vectors (AdCMV.Null and AAVCMV.luc) were not associated with increases in blood platelets with respect to administration of those vectors without concomitant administration of dexamethasone $(P>.08$ for comparisons at all time points of AdCMV.Null and dexamethasone with AdCMV.Null but no dexamethasone, Fig $6 ; P>.2$ for comparisons at all time points of AAVCMV.luc and dexamethasone with AAVCMV.luc but no dexamethasone, Fig 7).

\section{Discussion}

With the emergence of cardiac gene therapy strategies and the increasing success of gene transfer to animals, ${ }^{1-5,19-21}$ several challenges arise in adapting such strategies to clinical settings. The availability of vectors with differing pharmacokinetics would allow custom tailoring in the therapeutic armamentarium to meet the needs of the cardiac disease processes in question. This study demonstrates differing pharmacokinetics of AAV and Ad vector-mediated myocardial transfer of the same mTPO complementary DNA driven by different promoters, the CMV constitutive early promoterenhancer and a regulatable chimeric GRE promoter. Although the CMV promoter results in more effective expression of the reporter complementary DNA, leading to a greater peak elevation of platelet levels integrated across time, the GRE promoter has the advantage of being exogenously controllable by a commonly used pharmacologic agent once gene transfer to the heart has been accomplished. The use of such a vector could allow delayed or repetitive transgene expression as dictated by clinical conditions.

One of the limitations of Ad-mediated gene transfer is the relatively short duration of expression (weeks to months). ${ }^{22}$ This is advantageous for angiogenesis applications to limit the potential for promiscuous angiogenesis or hemangioma formation ${ }^{23}$; for longterm cardiac therapy strategies, however, Ad vectors will have limited applications. To circumvent these 
limitations of Ad-mediated cardiac gene transfer, an AAV vector with a regulatable promoter controllable by exogenously administered pharmacologic agents would afford the advantage of long-term regulatable expression of a transgene once delivered to the heart, thus allowing the clinician to custom tailor the therapeutic regimen to the patient's clinical needs. These applications could be useful in the treatment of such chronic cardiac conditions as heart failure.

A variety of strategies have been devised to control in vivo expression of transferred genes and thus alter the pharmacokinetics of in vivo gene transfer vectors in the context of regulatable or inducible promoters. Many of these regulatable promoters use exogenously administered agents to control transgene expression and some use the physiologic milieu to control gene expression. Examples of the exogenous control promoters include the tetracycline-responsive promoter, a chimeric transactivator consisting of the DNA and tetracycline-binding domains from the bacterial tet repressor fused to the transactivation domain of herpes simplex virion protein $16^{24}$; a chimeric promoter with multiple cyclic adenosine monophosphate response elements superimposed on a minimal fragment of the $5^{\prime}$-flanking region of the cystic fibrosis transmembrane conductance regulator gene $^{25}$; the EGR1 radiation-inducible promoter ${ }^{26}$; and the chimeric GRE promoter used in this study, with 5 GREs from the rat tyrosine aminotransferase gene in tandem with the insertion of $\mathrm{Ad} 2$ major late promoter TATA box-initiation site. ${ }^{9}$ Examples of the physiologic control of promoters include a chimera of the thymidine kinase promoter and the thyroid hormone and retinoic acid-responsive element responsive to both exogenous and endogenous tri-iodothyronine ${ }^{27}$; complement factor 3 and serum amyloid A3 promoters responsive to inflammatory stimuli ${ }^{28}$; the grp78 and $\mathrm{BiP}$ stress-inducible promoter, a glucose-regulated protein that is inducible through glucose deprivation, chronic anoxia, and acidic $\mathrm{pH}^{29}$; and hypoxia-inducible factor 1 and a heterodimeric basic helix-loop-helix protein that activates transcription of the human erythropoietin gene in hypoxic cells, which has been shown to act as a regulatable promoter in the context of gene therapy in vivo. ${ }^{20}$

Finally, an interesting strategy of regulating gene expression in Ad-mediated gene therapy is to use 2 separate replication-deficient vectors with the promoter of the therapeutic gene, AdIL8.ßgal (Escherichia coli lac $Z$ reporter gene controlled by the $5^{\prime}$ flanking region of the human interleukin 8 gene, a promoter containing elements responsive to tumor necrosis factor- $\alpha$ ) in vector 1 controlled by the product of the expression cas- sette in vector 2, AdEGR1.TNF (used to direct the production of tumor necrosis factor under the control of the basal activity of the early growth response 1 promoter). ${ }^{10}$

Whereas the highly active constitutive CMV promoter used in the AdCMV.mTPO vector demonstrated an elevation in blood platelet levels, reaching peak levels 14 to 15 days after vector administration and returning to baseline by day 38 independent of dexamethasone administration, the chimeric GRE promoter in the AdGRE.mTPO vector was responsive to intermittent administration of dexamethasone with intermittent elevations of blood platelet levels concomitant with dexamethasone stimulation. Although the peak blood platelet levels progressively declined with each successive round of vector administration (probably as a result of loss of the vector genome resulting from host responses to the $\mathrm{Ad}$ vector ${ }^{22}$ ), these observations demonstrated intermittent exogenous control of a gene transferred to the heart. In the context of regulatable expression, the AAVGRE.mTPO vector was responsive to intermittent administration of dexamethasone with intermittent elevations of blood platelet levels concomitant with dexamethasone stimulation, reaching levels a minimum of 2.2-fold above baseline levels. In sharp contrast to the Ad vector expressing the $m T P O$ transgene, which may be limited in terms of duration of expression because of immune responses, the AAV vector demonstrated persistent elevations of peak platelet level to a minimum of 2.2-fold above baseline levels with each successive round of dexamethasone administration. In the context of cardiac gene therapy, with the advent of better vectors, promoters, and an expanding scope of disease processes amenable to gene therapy strategies, vectors of differing pharmacokinetics will be a useful means of controlling the timing and duration of myocardial gene therapy. With this evidence of the feasibility of regulatable expression of transgenes delivered to the myocardium and with evidence of the ability of vectors such as the AAV to provide long-term myocardial transgene expression, ${ }^{6}$ it is conceivable with this vector technology that transgenes, such as that for vascular endothelial growth factor, not only could be delivered at the time of coronary bypass but could be "turned on" months or even years later, at the time of a threatened graft closure.

We thank N. Mohamed for help in preparing the manuscript.

\section{REFERENCES}

1. Anderson WF. Human gene therapy. Science 1992;256:808-13.

2. Flotte TR, Carter BJ. Adeno-associated virus vectors for gene therapy. Gene Ther 1995;2:357-62. 
3. Gal D, Weir L, Leclerc G, Pickering JG, Hogan J, Isner JM. Direct myocardial transfection in two animal models: evaluation of parameters affecting gene expression and percutaneous gene delivery. Lab Invest 1993;68:18-25.

4. Giordano FJ, Ping P, McKirnan MD, Nozaki S, DeMaria AN, Dillmann WH, et al. Intracoronary gene transfer of fibroblast growth factor-5 increases blood flow and contractile function in ischemic region of the heart. Nat Med 1996;2:534-9.

5. Mack CA, Patel SR, Schwarz EA, Zanzonico P, Hahn RT, Ilercil A, et al. Biologic bypass with the use of adenovirus-mediated gene transfer of the complementary deoxyribonucleic acid for vascular endothelial growth factor 121 improves myocardial perfusion and function in the ischemic porcine heart. J Thorac Cardiovasc Surg 1998;115:168-76.

6. Lee LY, Zhou X, Patel SR, et al. Prolonged transgene expression in the rat myocardium mediated by an adeno-associated viral vector: implications for chronic cardiac therapy. Surg Forum 1998:49:215-6.

7. Boshart M, Weber F, Jahn G, Dorsch-Hasler K, Fleckenstein B, Schaffner W. A very strong enhancer is located upstream of an immediate early gene of human cytomegalovirus. Cell 1985;41: 521-30.

8. Jantzen HM, Strähle U, Gloss B, Stewart F, Schmid W, Boshart $\mathrm{M}$, et al. Cooperativity of glucocorticoid response elements located far upstream of the tyrosine aminotransferase gene. Cell 1987; 49:29-38.

9. Narumi K, Suzuki M, Song W, Moore MA, Crystal RG. Intermittent, repetitive corticosteroid-induced upregulation of platelet levels after adenovirus-mediated transfer to the liver of a chimeric glucocorticoid-responsive promoter controlling the thrombopoietin cDNA. Blood 1998;92:822-33.

10. Hersh J, Crystal RG, Bewig B. Modulation of gene expression after replication-deficient, recombinant adenovirus-mediated gene transfer by the product of a second adenovirus vector. Gene Ther 1995;2:124-31.

11. Rosenfeld MA, Yoshimura K, Trapnell BC, Yoneyama K, Rosenthal ER, Dalemans W, et al. In vivo transfer of the human cystic fibrosis transmembrane conductance regulator gene to the airway epithelium. Cell 1992;68:143-55.

12. Crystal RG, McElvaney NG, Rosenfeld MA, Chu CS, Mastrangeli A, Hay JG, et al. Administration of an adenovirus containing the human CFTR cDNA to the respiratory tract of individuals with cystic fibrosis. Nat Genet 1994;8:42-51.

13. Xiao X, Li J, Samulski RJ. Production of high-titer recombinant adeno-associated virus vectors in the absence of helper adenovirus. J Virol 1998;72:2224-32.

14. McLaughlin SK, Collis P, Hermonat PL, Muzyczka N. Adenoassociated virus general transduction vectors: analysis of proviral structures. J Virol 1988;62:1963-73.

15. Buttrick PM, Kaplan ML, Kitsis RN, Leinwand LA. Distinct behavior of cardiac myosin heavy chain gene constructs in vivo: discordance with in vitro results. Circ Res 1993;72:1211-7.

16. Chirgwin JM, Przybyla AE, MacDonald RJ, Rutter WJ. Isolation of biologically active ribonucleic acid from sources enriched in ribonuclease. Biochemistry 1979;18:5294-9.

17. Tso JY, Sun XH, Kao TH, Reece KS, Wu R. Isolation and characterization of rat and human glyceraldehyde-3-phosphate dehydrogenase cDNAs: genomic complexity and molecular evolution of the gene. Nucleic Acids Res 1985;13:2485-502.

18. Thomas PS. Hybridization of denatured RNA and small DNA fragments transferred to nitrocellulose. Proc Natl Acad Sci U S A 1980;77:5201-5.
19. Kitsis RN, Buttrick PM, McNally EM, Kaplan ML, Leinwand LA. Hormonal modulation of a gene injected into rat heart in vivo. Proc Natl Acad Sci U S A 1991;88:4138-42.

20. Forsythe JA, Jiang BH, Iyer NV, Agani F, Leung SW, Koos RD, et al. Activation of vascular endothelial growth factor gene transcription by hypoxia-inducible factor 1. Mol Cell Biol 1996; 16:4604-13.

21. French BA, Mazur W, Geske RS, Bolli R. Direct in vivo gene transfer into porcine myocardium using replication-deficient adenoviral vectors. Circulation 1994;90:2414-24.

22. Yang Y, Haecker SE, Su Q, Wilson JM. Immunology of gene therapy with adenoviral vectors in mouse skeletal muscle. Hum Mol Genet 1996;5:1703-12.

23. Springer ML, Chen AS, Kraft PE, Bednarski M, Blau HM. VEGF gene delivery to muscle: potential role for vasculogenesis in adults. Mol Cell 1998;2:549-58.

24. Ho DY, McLaughlin JR, Sapolsky RM. Inducible gene expression from defective herpes simplex virus vectors using the tetracycline-responsive promoter system. Brain Res Mol Brain Res 1996;41:200-9.

25. Suzuki M, Singh RN, Crystal RG. Regulatable promoters for use in gene therapy applications: modification of the $5^{\prime}$-flanking region of the CFTR gene with multiple camp response elements to support basal, low-level gene expression that can be upregulated by exogenous agents that raise intracellular levels of cAMP. Hum Gene Ther 1996;7:1883-93.

26. Hallahan DE, Mauceri HJ, Seung LP, Dunphy EJ, Wayne JD, Hanna NN, et al. Spatial and temporal control of gene therapy using ionizing radiation. Nat Med 1995;1:786-91.

27. Hayashi Y, DePaoli AM, Burant CF, Refetoff S. Expression of a thyroid hormone-responsive recombinant gene introduced into adult mice livers by replication-defective adenovirus can be regulated by endogenous thyroid hormone receptor. J Biol Chem 1994;269:23872-5.

28. Varley AW, Coulthard MG, Meidell RS, Gerard RD, Munford RS. Inflammation-induced recombinant protein expression in vivo using promoters from acute-phase protein genes. Proc Natl Acad Sci U S A 1995;92:5346-50.

29. Gazit G, Kane SE, Nichols P, Lee AS. Use of the stress-inducible grp78/bip promoter in targeting high level gene expression in fibrosarcoma in vivo. Cancer Res 1995;55:1660-3. 